\title{
EDUCAÇÃO DE JOVENS E ADULTOS: PELO FORTALECIMENTO DOS EDUCANDOS
}

\author{
Josenice Rocchigiani Matos ${ }^{1}$
}

RESUMO: Este paper aborda a necessidade de fortalecimento dos educandos que fazem parte da modalidade de educação de jovens e adultos na perspectiva da inclusão social através da informação sobre benefícios sociais e políticas públicas. Se considerarmos que a cidadania não é o horizonte mais amplo a ser alcançado pela humanidade, é possível refletir sobre a possibilidade de que ela possa cumprir o lugar de mediadora para a superação da sociedade capitalista. E é nesse sentido que propomos a discussão sobre políticas públicas para a EJA.

Palavras-chave: EJA. Educação de Jovens e Adultos. migração de alunos repetentes e/ou reprovados. defasagem escolar. juvenização.

ABSTRACT: This paper addresses the need to strengthen students who are part of the youth and adult education modality from the perspective of social inclusion through information about social benefits and public policies. If we consider that citizenship is not the broadest horizon to be reached by humanity, it is possible to reflect on the possibility that it can fulfill the role of mediator for the overcoming of capitalist society. And it is in this sense that we propose the discussion on public policies for EJA.

Keywords: EJA. Youth and Adult Education. migration of repeating and/or failing students. school lag. youth.

\section{INTRODUÇÃO}

Um modo de viver que se organiza nessas bases traz uma relação indissolúvel entre o econômico - sociedade civil - e a dimensão jurídico-política - emancipação política. A cidadania é tida como um sinônimo de liberdade. Liberdade é a possibilidade de escolher alternativas melhores e, também, possíveis de serem realizadas. A lógica a que são

\footnotetext{
1 Graduada em Filosofia pela Universidade Católica de Salvador-Ba (UCSAL - 1999); Especializada em Educação do Ensino Superior com Ênfase em Tecnologias Educacionais, pela Faculdade Batista Brasileira (FBB); mestre em Educação e Ciências Sociais, pela Universidad del Salvador (USAL, Buenos Aires, Argentina, 2018), com a dissertação "ACCESSO Y PERMANENCIA DE LOS ESTUDIANTES DE EJA EN BRASIL: DESAFIOS Y POSSIBILIDADES"; e doctoranda en Humanidad y Artes, con Ênfase em Educacion - Universidad Nacional de Rosario (UNR, Rosário, Argentina, em curso). ORCID: https://orcid.org/oooo-ooo3-2173-9368.E-mail: josenice_sena@yahoo.com.br.
} 
submetidos homens e mulheres em todo o mundo, não lhes permite essa escolha. Essa lógica atinge a todos, ainda que existam diferentes sociedades, países e culturas.

Submetidos a esse modo de estar no mundo estão todos os seres humanos, entretanto, para muitos, a igualdade decorrente da cidadania só acontece no plano formal. As condições objetivas a que estamos sujeitos determinam o acesso aos direitos instituídos. Os jovens e adultos que não tiveram e não têm acesso à educação, estão entre os que têm essa igualdade apenas no plano formal. Assim, continuamos a nos questionar quem são os jovens e adultos da EJA? Que concepções de EJA circulam em nosso cotidiano?

A concepção vigente acerca dos jovens e adultos da EJA é a de que eles são sujeitos de direitos e da falta, já o dissemos. É verdade, são homens e mulheres que vivenciam percursos de negação, mas que também vivenciam o protagonismo positivo, quando lutam, vencendo desafios que exigem conhecimentos os quais eles e elas não têm tido acesso.

Com todas as letras, o jovem e o adulto que não tiveram acesso à educação no sentido estrito/formal no passado, é o jovem e o adulto trabalhador de hoje. Ainda que todos tenham direito à educação, a negação desse direito se dá pelo lugar que o sujeito ocupa na sociedade: o lugar de classe. A educação é atribuída à tarefa de atenuar a exclusão social através da formação para a empregabilidade, preparando a população, em situação de pobreza extrema, para a situação de incerteza a que se submete a humanidade.

\section{FUNDAMENTAÇÃO TEÓRICA}

Suplência é o regime de ensino instituído, legalmente, pela Lei Federal 5692, de in de agosto de 1971, Capítulo IV, onde encontramos as definições e atribuições do Ensino Supletivo, dividido em duas modalidades básicas - cursos e exames - que se dividem em quatro funções: Suplência, Suprimento, Aprendizagem e Qualificação.

Falar do Ensino Supletivo é falar que as classes populares sofrem na estrutura de ensino que lhes é oferecida, era contradição com as promessas e intenções virtuais da lei.

\footnotetext{
A Educação de Jovens e Adultos (EJA), no caso brasileiro, se constituiu muito mais como produto da miséria social do que do desenvolvimento. É consequência dos males do sistema público regular de ensino e das precárias condições de vida da maioria da população, que acabam por condicionar o aproveitamento da escolaridade na época apropriada, é este marco condicionante - a miséria social que acaba por definir as diversas maneiras de se pensar e realizar a EJA. (INEP, 1992, p.3)
}

A realidade do trabalhador estudante é diferente da realidade do aluno do Ensino Fundamental diurno. $O$ trabalhador estudante se refere aos alunos que não tiveram oportunidade de completar sua escolaridade fundamental, obrigatória e regular, na idade de o7 a I4 anos, por várias razões. Ele foi "excluído" (FERRARI, 1987) da escola por razões econômicas, pois precisava trabalhar para ajudar no sustento da família. Assim, muitos tiveram que mudar de cidade tentando uma "vida melhor" em outro lugar, ou repetiram várias vezes às primeiras séries do Primeiro Grau, muitas vezes, pela incompetência do sistema de ensino regular, que parece não saber trabalhar com as diferenças, em especial, do trabalhador estudante. 
Marginalizando este aluno na sua miséria histórica e socialmente herdada, e sem oportunidades reais de acompanhar um trabalho pedagógico elaborado para outros segmentos culturais das classes dominantes, a escola fundamental diurna não consegue acolher muitos de nossos jovens, e ao completarem I4 anos, são "expulsos", a situação os coloca para fora do sistema, encaminhados para os cursos de Suplência I.

\begin{abstract}
Uma massa considerável de excluídos do sistema formal de ensino, seja por se encontrar em condições de vida precárias, seja por ter tido acesso a uma escola de má qualidade, ou mesmo não ter tido acesso a escola, acaba por se defrontar com a necessidade de realizar sua escolaridade já como adolescentes ou adultos para sobreviver em uma sociedade onde o domínio do conhecimento ganha cada vez mais importância. (INEP, 1992, p. 4).
\end{abstract}

O voltar/continuar a estudar para este trabalhador estudante tem duplo significado: resgatar um direito à cidadania que lhe negaram no passado e garantir a sobrevivência presente e futura. A questão de sua sobrevivência é muito mais importante e significativa do que para um estudante de 7 a 14 anos, uma vez que na sociedade capitalista, a obtenção/permanência de um trabalho obedece a critérios comandados pelas leis de mercado, que são conjunturais e atende aos interesses do capital.

A classe trabalhadora brasileira vivência diferentes processos de precarização do trabalho - terceirização, subcontratação, informalidade e ilegalidade - reforçando a situação de pobreza como horizonte certo. O Brasil é o quinto país mais populoso do mundo, com mais de 200 milhões de habitantes, é o oitavo país em desigualdade social, com os $10 \%$ mais ricos acumulando quase $47 \%$ da renda nacional. Temos, ainda, "uma população pobre de II,I milhões de famílias - 21\% da população, e a população extremamente pobre: 4,2 milhões de famílias o que corresponde a $8,2 \%$ da população" (SPOSATI, 2006, p. 9 - 17).

Esses homens e mulheres vivenciam cotidianamente a exclusão no que diz respeito à efetivação dos direitos sociais - educação, saúde, habitação, lazer - dentre outros. $\mathrm{O}$ modo de vida que se funda na exploração e na dominação, a educação pode ser em muitas situações o instrumento real de enfrentamento a este sistema. Excluir para incluir é próprio da lógica do capitalismo. O princípio inclusão-exclusão é caracterizado como afirma Oliveira, (2004, p.I44), "constitutivo do sistema do capital não só no plano histórico, mas também no plano lógico. [...] o conceito de exclusão só adquire sentido no interior de uma totalidade complexa orientada na perspectiva da sociedade de classes"

Assim, "viver como excluído pode ser uma forma de inclusão possível em um mundo desigual" (SPOSATI, 2006, p. I). A desigualdade social permanece em nossa sociedade com a presença de "uma sub-humanidade incorporada através do trabalho precário, do trambique, do pequeno comércio, no setor de serviços mal pagos ou até mesmos escusos" (MARTINS, 1997, p.37).

A exclusão social para o indivíduo resulta em solidão, isolamento e estigma e, para a sociedade, ameaça à coesão social. Conforme, Escorel (I999, p. I8), a condição de exclusão é aquela em que o indivíduo está "sem lugar no mundo", totalmente desvinculado ou com vínculos tão frágeis e efêmeros que não constituem uma unidade social de pertencimento.

Essa forma de viver exige a tomada de decisões que resultem em medidas de proteção social, especialmente, para aqueles que estão submetidos à extrema desigualdade 
social. Proteção social na forma de políticas cambiais, fiscais, monetárias, dentre outras políticas públicas. Todas, entretanto, dentro da lógica de manutenção do sistema capitalista.

A efetivação do direito à educação para todos os jovens e adultos reivindica um processo de lutas para sua consolidação; para isso, não é o bastante a sua instituição na Carta Magna, seus portadores precisarão exigi-lo. Trata-se da justiciabilidade, isto é, da possibilidade de cobrar um direito violado, em juízo.

Afirma, Cury, (200o, pg.575), “o ensino fundamental obrigatório deve ser universalmente atendido em relação a crianças e adolescentes de 7 a 14 anos. Maiores de I5 anos têm idêntico direito, mas só o usufruem na medida em que o exigem". Em 1996, o Ensino Fundamental incluiu as crianças a partir de seis anos, mantendo o limite dos 14 anos. Entretanto, na ótica da obrigatoriedade, reafirma Cretela:

\footnotetext{
O art. 208, § Iำ, da Constituição vigente não deixa a menor dúvida a respeito do acesso ao ensino obrigatório e gratuito que o educando, em qualquer grau, cumprindo os requisitos legais, tem o direito público subjetivo, oponível ao Estado, não tendo este nenhuma possibilidade de negar a solicitação, protegida por expressa norma jurídica constitucional vigente (CRETELA, 1993, p. 418).
}

Do ponto de vista jurídico "o mandado de segurança coletivo, o mandado de injunção e a ação civil pública" - mecanismos declaratórios e garantidores do Direito à Educação - na prática, não vêm sendo efetivados como instrumentos previstos em lei para que o cidadão possa acionar o Estado no que se refere à garantia dos direitos instituídos (OLIVEIRA, I998, p. 65). Essa situação ocorre pela falta de conhecimento, pela descrença do indivíduo no cumprimento da norma;

Esta violação de direitos não afeta a todos de maneira igual. Historicamente, a educação de jovens e adultos tem sido tratada pelo poder público como política compensatória, de caráter assistencial, e não como um direito humano (HADDAD, 2003, p. or).

Ainda que reconheçamos a validade do alcance do status de sujeitos de direitos para todos os homens e mulheres, independente do tempo de vivência - da infância, adolescência, juventude e da vida adulta - a relação de exclusão e de inclusão necessária à forma de viver regida pela lógica da cidadania, regula o acesso aos direitos instituídos, dentre eles, à educação. Não se trata mais da negação do direito, este já foi reconhecido, porém, a educação reservada aos jovens e adultos trabalhadores, no Brasil, é aquela que se ampara no ideário da UNESCO para a Educação de Adultos - educação como instrumento para diminuir as desigualdades sociais. Assim,

[...] são formulados novos discursos capazes de ordenar aspirações, sonhos, fantasias projetivas, necessidades materiais e simbólicas. A força do discurso neoliberal se destaca ainda mais devido à ausência de formulações culturais ideológicas concorrentes na disputa por hegemonia. Esse destaque decorre, também, da própria recomposição das formas de produção que, geradoras de diversos processos de exclusão, legitimam, no plano das subjetividades, a aceitação, e mesmo o desejo de ver implantadas medidas de caráter mercantil 
apregoadas como solucionadoras dos problemas vivenciados por parte significativa da sociedade (RUMMERT, 2000, p. 58).

Em diferentes governos, no Brasil a política pública, no que diz respeito ao EJA, tem as marcas da descontinuidade e do retrocesso. No momento posterior ao regime militar, o primeiro presidente eleito (1989), Fernando Collor de Melo, proclama um discurso de mobilização da sociedade por meio de órgãos governamentais e não governamentais em prol da alfabetização de crianças, jovens e adultos. Nesse intuito, extingue a Fundação Educar e realiza o Programa Nacional de Alfabetização e Cidadania (PNAC).

A Fundação Educar havia sido implantada em lugar do Movimento Brasileiro de Alfabetização (MOBRAL), criado em 1969, que se constituiu como "um programa de proporções nacionais, proclamadamente voltado a oferecer alfabetização a amplas parcelas dos adultos analfabetos nas mais variadas localidades do país" (DI PIERRO; ORLANDO; RIBEIRO, 200I, p. 6I).

No governo de Itamar Franco, nos anos 90, diante das pressões nacional e internacional, discutiu-se a implementação do Ensino Fundamental para Jovens e Adultos. Foi o momento do Plano Decenal de Educação para Todos, para o período de 1993 a 2003, bem como do projeto de Lei de Diretrizes e Bases da Educação Nacional, em 1994.

Também nas palavras de Di Pierro; Orlando; Ribeiro (2001), em 1996, o governo de Fernando Henrique Cardoso, dando continuidade ao retrocesso em relação às políticas da EJA, manifesta-se, dentre outras questões, por meio de uma emenda à Constituição, quando manda suprimir a obrigatoriedade do ensino fundamental aos jovens e adultos, permanecendo somente a gratuidade de sua oferta. Nos oito anos desse Governo, o MEC, em acordo com a lógica econômica da política neoliberal para a América Latina, prioriza o Ensino Fundamental para as crianças e a política para a EJA era inexistente.

A Lei de Diretrizes e Bases da Educação Nacional (LDBEN) 5692/71 dispôs sobre as regras básicas relativas à educação supletiva, isto é, ao ensino aos jovens e adultos, o que se constituiu como uma inovação na medida em que, pela primeira vez, a legislação educacional aborda o segmento EJA. A modalidade EJA é instituída, rompe-se com a concepção de suplência, no entanto, no correspondente ao Ensino Fundamental, deixa de ser obrigatória para os maiores de 15 anos ou para aqueles que não tiveram acesso à educação, na faixa de idade de 7 a 14 anos.

Assim, sua oferta se constitui como dever de Estado, "reitera a obrigatoriedade como consequência do dever do Estado, sendo esta, portanto, uma diretriz legal, ainda que não mais constitucional" (BRASIL / MEC, 200o, p. o9). Em seu texto, a LDBEN traz as funções de suplência, suprimento e qualificação, significando, respectivamente, reposição de escolaridade, aperfeiçoamento ou atualização e formação para o trabalho e profissionalização.

Em 1996, a nova LDBEN - Lei no 9.394, amparada nos princípios de centralidade das decisões, descentralização de ações e de responsabilidades quando da execução, imprime às políticas públicas o caráter compensatório. A EJA é posta em lugar secundário quando da instituição do Fundo de Manutenção e Desenvolvimento do Ensino Fundamental e Valorização do Magistério (FUNDEF) e a Reforma da Educação Profissional, por meio do Decreto 2.208/97. A Lei no 9.394/1996 reitera o caráter supletivo 
da EJA, quando em seu texto refere-se a "cursos e exames supletivos" (Art. 38), perpetuando, portanto, a concepção de suplência, de correção de fluxo escolar e de compensação (RUMMERT; VENTURA, 2007, p. 32).

$\mathrm{Na}$ década de 90 , as políticas públicas na educação e, por extensão, na EJA decorrem dos ditames dos organismos internacionais, leiam-se, UNESCO, BIRD/Banco Mundial, com foco em seus programas de ajuste estrutural, resultado de "uma intervenção consentida realizada pelas autoridades educacionais nos moldes das agências multilaterais, no contexto da universalização do capitalismo, direcionadas por uma razão instrumental e pela busca de consenso social geral” (SILVA JR., 2002, p. 206).

\section{MATERIAIS E MÉTODOS}

Trata-se de uma revisão bibliográfica com método qualitativo e descritivo baseando-se em livros e artigos científicos publicados sobre os objetivos geral e secundários elencados para esse estudo.

Inicialmente será feita uma pesquisa em livros de educação para construção dos capítulos, posteriormente, será realizada uma pesquisa na SCIELO e no portal de Dissertações e teses, Domínio Público.

\section{RESULTADOS E DISCUSSÃO}

A lógica das políticas públicas da EJA continua com as marcas históricas de uma modalidade educacional caracterizada pelo aligeiramento, com foco na correção da defasagem idade-série e na redução dos baixos índices de escolaridade da população de jovens adultos. $O$ assistencialismo, ainda é uma estratégia utilizada nas diferentes iniciativas e a efetivação do direito à educação não se constitui realidade.

Os problemas estruturais da EJA ainda não foram vencidos. O caráter de suprir necessidades daqueles que não tiveram acesso à educação, na considerada "idade própria" - como se o homem não pudesse aprender em todos os tempos da infância, da adolescência, da juventude e do adulto - é a própria história da EJA no país.

As políticas públicas voltadas para a EJA, no Brasil, têm como foco a efetivação do direito à educação. Entretanto, os dados têm demonstrado que jovens e adultos continuam excluídos desse processo. Como mencionamos antes, o contingente de jovens e adultos submetidos à negação ou ao fracionamento da possibilidade da educação no sentido estrito/formal, nos tempos da infância ou da adolescência, compõe um coletivo diverso, no que se refere à geração, à raça e à etnia, às questões de gênero, mas todos eles são sujeitos pertencentes à classe trabalhadora. Grande parte vive na pobreza extrema, submetidos à desigualdade social que caracteriza o modo de viver daqueles que, pelo lugar que ocupam na sociedade, são vítimas das "explorações e expropriações" (VENTURA, 2008, p. 237).

Percebe-se, assim a adoção de uma concepção de política pública centrada na perspectiva das "múltiplas identidades e subjetividades", vertente que compreende a EJA como um "campo de demonstração unicamente da diversidade cultural". Porém, no nosso entendimento, a EJA deve ser concebida em uma ótica na qual se situam as diversidades de gênero, geração, raça e etnia e, também, na "análise das diferenciações sociais sob a forma de classe" (VENTURA, 2008, p. 237). 
O discurso instituído diz de uma educação para a cidadania, porém,

[...] educar para a cidadania é formar para uma dupla ilusão: primeira, porque é impossível atingir a plenitude da cidadania (visto que o fosso entre ricos e pobres aumenta em vez de diminuir); segunda, porque mesmo que isto fosse possível, não levaria à formação de pessoas efetivamente livres, efetivamente sujeitos da história, dada a natureza própria da cidadania (TONET, 2005, p. 130).

A crise de natureza estrutural em relação ao capitalismo tem resultado em piora das condições de vida de homens e mulheres. No bojo dessa situação, a educação necessária é aquela que reproduz a lógica da manutenção do poder de alguns sobre a maioria.

Segundo Faleiros (2002, p. 78), "Quando um determinado sujeito procura ou se vê diante do Serviço Social, ele está numa trajetória de fragilização, de perda de patrimônio ou referencias, sem o atendimento de suas necessidades básicas [...]”. O processo de implementação e execução do projeto de intervenção aconteceu de forma gradual, onde cada etapa do plano de ação foi executada, devido a algumas intercorrências, o projeto teve que sofrer ajustes em relação a realização dos grupos e da palestra prevista no cronograma.

A implantação do balcão social pode abrir um novo espaço para os alunos, que muitas vezes passavam no serviço social, para esclarecer alguma dúvida, mas em muitas situações o motivo real era outro. Então neste espaço alguns alunos chegavam e relatavam durante os atendimentos os seus problemas e aflições, enquanto outros realmente só procuravam para alguma informação ou encaminhamento em relação aos serviços, programas e projetos ofertados pelo município.

\section{CONCLUSÃO}

A política pública da EJA, no Brasil, no contexto atual, ampara-se na concepção da EJA como direito e dever do Estado. Também na crença de que o jovem e adulto, que não teve acesso à educação no sentido estrito/formal, é um sujeito de direito. A luta que temos empreendido é aquela do acesso universal à educação. $O$ que buscamos é a ampliação do acesso para todos, de direitos e políticas sociais.

A universalidade da educação, nessa lógica, constitui-se como uma utopia na medida em que a igualdade autorizada pela cidadania, como dissemos, acontece apenas no campo formal. O caráter de impossibilidade da universalização da educação é próprio do capital, uma vez que impulsiona sua efetivação e, ao mesmo tempo, impõe limites à sua concretização. A transformação dessa ordem não cabe à educação ou às políticas públicas, mas ao trabalho, porque a sociabilidade é determinada pelo modo como os homens produzem sua existência.

\section{REFERÊNCIAS}

CRETELlA Jr., J. Comentários à Constituição Brasileira de 1988. V. 8, 2. ed. Rio de Janeiro: Forense, 1993. 
DI PIERRO, M. C.; ORLANDO, J.; RIBEIRO, V. M. Visões da Educação de Jovens e Adultos no Brasil. In.: Cad. CEDES, Campinas, v. 21, n. 55 nov. 20or. Disponível em: $<$ http://www.scielo.br/scielo.php?script=sci_arttext\&pid=Soror-

$32622001000300005 \& \operatorname{lng}=p t \& n r m=$ iso $\&$ tlng=pt\%2523backI $>$. Acesso em: jun. 202I

FERRARI, Alceu Ravanello. Analfabetismo no Brasil: Tendência secular e avanços recentes. Cadernos de Pesquisa, São Paulo, n. 52, p. 53-49, fev. 1985

HADDAD, Sérgio. Papel do atendimento de jovens e adultos no Estado de São Paulo. ANPED, i6o Reunião Anual, 1993.

INEP. Instituto Nacional de Estudos e Pesquisas Educacionais. Brasília, 56, out/dez, 1992.

MARTINS, Eliana Bolorino Carteiro.O Serviço Social na Área da Educação. In: Revista Serviço Social e Realidade.V8 № ı.UNESP,franca.São Paulo,1999. Disponível em: http://partes.com.br \educação \escolaeserviçosocial.asp. Acesso em: jun. 202I

OLIVEIRA, A. da R. Marx e a Exclusão. Pelotas: Seiva, 2004.

RUMMERT, S. M. Educação e identidade dos trabalhadores: concepções do capital e do trabalho. São Paulo: Xamã; Niterói: Intertexto, 2000.

SPOSATI, A. O primeiro ano do Sistema Único de Assistência Social- SUAS: In Revista Serviço Social e Sociedade n.87, SP., Cortez editora, 2006.

VENTURA. J. P. Educação de Jovens e Adultos ou Educação da Classe Trabalhadora? Concepções em disputa na Contemporaneidade Brasileira. Tese Doutorado Programa de Pós-Graduação em Educação da Universidade Federal Fluminense, Campo de Confluência: Trabalho e Educação. Niterói, 2008. Disponível em: http://www.uff.br/pos_educacao/joomla/images/stories/Teses/ventura.pdf. Acesso em: jun. 2021 